Marquette University

e-Publications@Marquette

8-2009

\title{
Structure - property relationships of new polystyrene nanocomposites prepared from initiator-containing layered double hydroxides of zinc aluminum and magnesium aluminum
}

Charles Manzi-Nshuti

Marquette University

Dan Chen

Hunan Normal University

Shengpei Shu

Hunan Normal University

Charles A. Wilkie

Marquette University, charles.wilkie@marquette.edu

Follow this and additional works at: https://epublications.marquette.edu/chem_fac

Part of the Chemistry Commons

\section{Recommended Citation}

Manzi-Nshuti, Charles; Chen, Dan; Shu, Shengpei; and Wilkie, Charles A., "Structure - property relationships of new polystyrene nanocomposites prepared from initiator-containing layered double hydroxides of zinc aluminum and magnesium aluminum" (2009). Chemistry Faculty Research and Publications. 90.

https://epublications.marquette.edu/chem_fac/90 
Marquette University

\section{e-Publications@Marquette}

\section{Chemistry Faculty Research and Publications/College of Arts and Science}

This paper is NOT THE PUBLISHED VERSION; but the author's final, peer-reviewed manuscript. The published version may be accessed by following the link in the citation below.

Polymer Degradation and Stability, Vol. 94, No. 8 (August, 2009): 1290-1297. DOI. This article is (C) Elsevier and permission has been granted for this version to appear in $\mathrm{e}-$ Publications@Marquette. Elsevier does not grant permission for this article to be further copied/distributed or hosted elsewhere without the express permission from Elsevier.

\section{Structure-property relationships of new polystyrene nanocomposites prepared from initiator-containing layered double hydroxides of zinc aluminum and magnesium aluminum}

Charles Manzi-Nshuti

Department of Chemistry and Fire Retardant Research Facility, Marquette University, Milwaukee, WI Dan Chen College of Chemistry and Chemical Engineering, Hunan Normal University, China Shengpei Su College of Chemistry and Chemical Engineering, Hunan Normal University, China Charles A. Wilkie Department of Chemistry and Fire Retardant Research Facility, Marquette University, Milwaukee, WI 


\begin{abstract}
Polystyrene/layered double hydroxides (PS/LDHs) nanocomposites were prepared by free radical polymerization of styrene monomer in the presence of LDHs intercalated with 4,4'-azobis(4cyanopentanoate) anions (LDH-ACPA). XRD and ATR-IR are used to confirm that the materials produced are layered and the presence of the azo-initiator anions in these LDHs. These LDHs were used successfully to polymerize styrene and both XRD and TEM images of the composites support the formation of a mixed exfoliated-intercalated nanocomposite for ZnAl-ACPA but a microcomposite for MgAl-ACPA. The magnesium-containing LDHs decreased the glass transition temperature ( $\left.T_{\mathrm{g}}\right)$ of the composites while $\mathrm{ZnAl}-\mathrm{ACPA}$ did not affect $T_{\mathrm{g}}$ significantly. The $T_{\mathrm{g}}$ depression is related to enhanced polymer dynamics due to the extra free volume at the $\mathrm{LDH}$ additive-polymer interface. A reduction in the onset of thermal decomposition temperature was observed in PS/LDH compared to neat PS, likely due to the early decomposition of the LDH. The fire performance, as evaluated by the cone calorimeter, reveal that PS-ZnAl-ACPA shows enhanced fire properties compared to PS-MgAl-ACPA.
\end{abstract}

\title{
Keywords
}

Nanocomposites; Layered double hydroxides; Fire retardancy; Polystyrene

\section{Introduction}

Layered double hydroxides (LDHs), also known as hydrotalcite-like materials, consist of positively charged brucite $\left[\mathrm{Mg}(\mathrm{OH})_{2}\right]$-like layers with divalent cations partially substituted by trivalent cations in octahedral sites, separated by interlayer anions and water molecules $\underline{[1]}$, [2]. Their ideal structure is represented by the formula $\left[\mathrm{M}^{\prime \prime}{ }_{1-\mathrm{x}} \mathrm{M}^{\prime \prime \prime}{ }_{\mathrm{x}}(\mathrm{OH})_{2}\right]_{\text {intra }}\left[\mathrm{A}^{\mathrm{m}-}{ }_{\mathrm{x} / \mathrm{m}} \mathrm{nH}_{2} \mathrm{O}\right]_{\text {inter, }}$, where intra and inter denote the intralayer crystalline domain and the interlayer space, respectively; $\mathrm{M}^{\prime \prime}$ is a divalent cation, such as $\mathrm{Mg}$, $\mathrm{Co}, \mathrm{Ni}, \mathrm{Cu}$, or $\mathrm{Zn}$; $\mathrm{M}^{\prime \prime \prime}$ is a trivalent cation, such as $\mathrm{Al}, \mathrm{Cr}, \mathrm{Fe}, \mathrm{V}$, or $\mathrm{Ga}$; charge neutrality is achieved by the presence of $\mathrm{A}^{\mathrm{m}-} \mathrm{m}$-valent anions, such as $\mathrm{NO}_{3}{ }^{-}, \mathrm{CO}_{3}{ }^{2-}, \mathrm{Cl}^{-}, \mathrm{SO}_{4}{ }^{2-}, \mathrm{C}_{12} \mathrm{H}_{25} \mathrm{SO}_{4}{ }^{-}$, etc., which exist hydrated in the interlayer spacing.

Because of their highly tunable properties, LDHs are considered a new emerging class of possibly favorable layered materials for the preparation of multifunctional polymer/layered nanocomposites ${ }^{[3]}$. Incorporation of inorganic nanoparticles in a polymer matrix can significantly affect the thermal, mechanical, optical, electrical, magnetic and flammability properties ${ }^{[4]}{ }^{[5]}$. Additionally, nanocomposites have many advantages, such as increased strength (without compromising other mechanical properties), improved heat resistance, decreased gas permeability, and enhanced electrical conductivity, over traditional polymer composites prepared with fillers in the micrometer size domain ${ }^{[6]}$. The properties of polymer nanocomposites depend on the type of incorporated nanoparticles, their size and shape, as well as the concentration and interaction with polymer matrix $[7],[8],[9]$.

The incorporation of fillers into a polymer matrix can bring about changes in the mechanical and thermal characteristics of the resulting composite. One benchmark used to compare the thermal behavior of composites is the glass transition temperature, $T_{\mathrm{g}}$. Most researchers report an increase in the $T_{\mathrm{g}}$ as

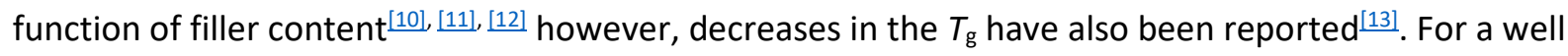
dispersed system, even low filler volume fractions provide an enormous amount of interfacial area

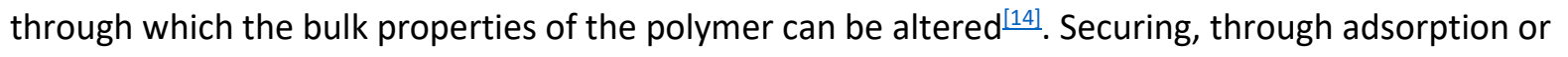
grafting, the polymer onto a surface restricts the molecular mobility of the affected chains, changes the 
density of packing of the polymer chains, and modifies the conformation and orientation of chain segments in the neighborhood of the surface ${ }^{[15]}$. On the other hand, interfaces characterized by greater

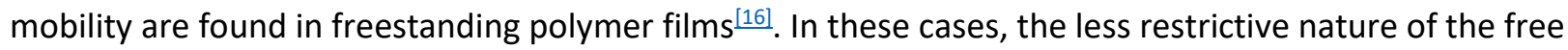
surface can increase the segmental mobility at the air/polymer interface.

While strong electrostatic interactions between LDH layers via gallery anions make the complete exfoliation of the LDH layers difficult, recently, a few studies have been performed in which exfoliated $\mathrm{LDH} /$ polymer nanocomposites have been achieved. Wang et al. prepared disordered exfoliated LDHs/PMMA nanocomposites by in situ bulk polymerization and observed an enhancement of the glass transition temperature and the decomposition temperatures compared to pristine PMMA $\frac{[17]}{}$. Qiu et al. reported exfoliation of LDH in polystyrene by in-situ atom transfer radical polymerization using an initiator-modified LDH precursor. The decomposition temperature of resulting polymer/LDH composite was found to be $45^{\circ} \mathrm{C}$ higher than that of pure PS when $50 \mathrm{wt} \%$ weight loss is selected as a comparison point $\frac{[18]}{\text {. }}$.

The addition of LDHs to polymers has also allowed the formation of new types of fire retardants. The efficacy of LDHs is exemplified by reductions in peak heat release rates above $50 \%$ obtained when selected LDHs were combined with poly(methyl methacrylate) $\underline{[19],}, \underline{[29]}$, polyethylene $\underline{[21]}, \underline{[22]}$ and polypropylene ${ }^{[23]}$. With these non-polar polymers, the use of LDHs modified with long chains, like stearate or oleate, was found to be advantageous for fire properties. A study of the combination of a series of long chain carboxylate MgAl LDHs with polystyrene revealed contradictory results in fire performance ${ }^{[20]}$; the lowest reductions in PHRR were obtained with C-22 and C-18 while C-10 and C-12 LDHs gave large reductions for the PS composites $(>50 \%)$, results comparable to those of well dispersed PS/MMT systems ${ }^{[24]}$. In another investigation, while the combination of MgAl-undecenoate LDH with PS gave modest improvements in fire properties, synergistic effects in both TGA and cone calorimetry were observed for formulations containing both MgAl-undecenoate LDH and ammonium polyphosphate ${ }^{[25]}$.

In the current study, ZnAl and MgAl LDHs intercalated with an azo-initiator anion of 4,4'-azobis(4cyanopentanoic acid) (Fig. 1) are prepared and used to prepare polystyrene nanocomposites. This investigation explores how these LDH nanofillers affect dispersion, molecular weight, glass transition, thermal stability and fire performance of their polystyrene nanocomposites.

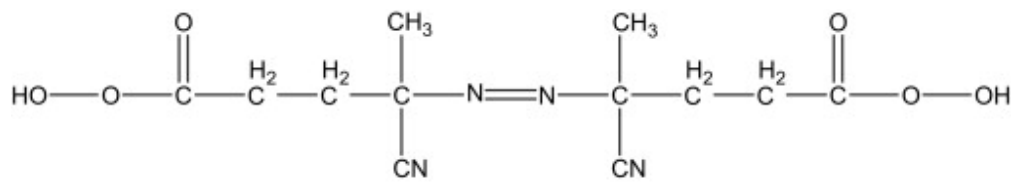

Fig. 1. Idealized structure of 4,4'-azobis(4-cyanopentanoic acid) (ACPA).

\section{Experimental}

\subsection{Materials}

Styrene monomer, inhibitor remover columns, zinc nitrate hexahydrate, $(98 \%)$, magnesium nitrate hexahydrate, (99\%), aluminum nitrate nonahydrate, (98\%) and 4,4'-azobis(4-cyano-valeric acid), (75+\%), were all obtained from Aldrich Chemical Co. Sodium hydroxide was purchased from Acros Organics. All chemicals were used without further purification. 


\subsection{Preparation of the ACPA-LDHs}

The $\mathrm{Zn} / \mathrm{Al}$ and $\mathrm{Mg} / \mathrm{Al} \mathrm{LDH}$ s intercalated with 4,4'-azobis(4-cyano-valerate) anion were synthesized by the literature coprecipitation method ${ }^{[26]}$ with some modifications. The preparation was carried out in an $\mathrm{N}_{2}$ atmosphere and the distilled water used in the preparation was boiled for $30 \mathrm{~min}$ and cooled to room temperature under $\mathrm{N}_{2}$ before use to exclude $\mathrm{CO}_{2}$ whose presence would lead to the incorporation of carbonate in the LDHs. Magnesium nitrate $(0.2 \mathrm{~mol})$ and aluminum nitrate $(0.1 \mathrm{~mol})$ were dissolved in $450 \mathrm{ml}$ of distilled water. The nitrate solution was then slowly dropped into a vigorously stirred $900 \mathrm{ml}$ water solution of 4,4'-azobis(4-cyano-valeric acid) $(0.2 \mathrm{~mol})$ and sodium hydroxide $(0.2 \mathrm{~mol})$. The $\mathrm{pH}$ of the solution was maintained at 10 by adding $1 \mathrm{M} \mathrm{NaOH}$ solution. After the addition of the nitrate solution, the resulting precipitate was aged at room temperature for 7 days, and was then filtered until all the supernatant liquid was removed. The sample was washed several times with distilled water and dried at room temperature for 1 day and at $40{ }^{\circ} \mathrm{C}$ in a vacuum oven for $24 \mathrm{~h}$. All operations were performed under nitrogen.

\subsection{Preparation of PS/LDH-ACPA composites}

The PS nanocomposites of ZnAl-ACPA and MgAl-ACPA were prepared by in situ polymerization; the composition of each nanocomposite is calculated from the amount of layered double hydroxide and the styrene monomer combined in a $400 \mathrm{ml}$ beaker before polymerization. Briefly, the appropriate LDH loading was combined with styrene, total weight $140 \mathrm{~g}$, in a $400 \mathrm{ml}$ beaker covered with aluminum foil, and the mixture was stirred vigorously for 1 day. Then, the mixture was heated to $100^{\circ} \mathrm{C}$ until the mixture has become viscous; then, the temperature was further increased to $120^{\circ} \mathrm{C}$ for $8 \mathrm{~h}$. At the end, the polymer was placed overnight in a vacuum oven at $100{ }^{\circ} \mathrm{C}$ to remove unreacted monomer and yield the LDH/PS nanocomposites. For the two types of LDHs prepared in this study, the LDH loadings used with PS were 3, 6, and $10 \%$. As control experiments, styrene monomer (no initiator) and a combination of an organically-modified $\mathrm{Zn} \mathrm{n}_{2} \mathrm{Al} \mathrm{LDH}$ (anion = undecenoate) that is typically not a good candidate for initiating free radical polymerization (5\%) with styrene, were also submitted to the above conditions to test the possibility of thermal polymerization of styrene under these conditions. With these control styrene solutions, polymerization did not occur even when the solutions were further heated to $110^{\circ} \mathrm{C}$ for an additional $96 \mathrm{~h}$.

\subsection{Characterization of LDH and PS/LDH systems}

Fourier transform infrared (FTIR) spectra of the solid materials were obtained on a Bruker Tensor 27 series, with a Pike Miracle ATR accessory using a ZnSe crystal.

Thermogravimetric analysis (TGA) was performed on a Netzsch TG 209 F1 instrument at the 15 mg scale under a flowing air or nitrogen atmosphere at a scan rate of $20^{\circ} \mathrm{C} / \mathrm{min}$. TGA experiments were done in duplicate and the averages are reported. X-ray diffraction measurements (XRD) were performed on a Rigaku Miniflex II desktop X-ray diffractometer; data acquisition was performed using a scan speed of $2 \% \mathrm{~min}$, at a sampling width of $0.020^{\circ}$ from 2 to $40(2 \vartheta)$ for LDHs and 2 to $10(2 \vartheta)$ for polymeric samples. Bright field transmission electron microscopy (TEM) was performed on a JEOL 1230 MSC SI033 microscope equipped with a Tietz F224 digital camera, operated at an accelerating voltage of $100 \mathrm{kV}$. Cone calorimeter measurements were performed on an Atlas CONE-2 according to ASTM E 1352 at an incident flux of $35 \mathrm{~kW} / \mathrm{m}^{2}$, using a cone shaped heater; the exhaust flow was set at $24 \mathrm{l} / \mathrm{sec}$. The specimens for cone calorimetry were prepared by the compression molding of the sample (about $30 \mathrm{~g}$ ) into $3 \times 100 \times 100 \mathrm{~mm}^{3}$ square plaques. Typical results from cone calorimetry are reproducible to within 
about $\pm 10 \%$; these uncertainties are based on many runs in which thousands of samples have been combusted $[27]$.

\subsection{Glass transition measurements and molecular weights}

The glass transition temperatures $\left(T_{\mathrm{g}} \mathrm{s}\right)$ of the pure polymers and various PS/LDH composites were characterized using a differential scanning calorimeter (DSC822 Mettler Toledo using a FRS5 ceramic sensor). All samples were subjected to the following heating/cooling profile: the sample was heated from 30 to $130^{\circ} \mathrm{C}$ at $20^{\circ} \mathrm{C} / \mathrm{min}$ and then cooled at $20^{\circ} \mathrm{C} / \mathrm{min}$ back to $30^{\circ} \mathrm{C}$. This sample was maintained for $50 \mathrm{~s}$ at $30^{\circ} \mathrm{C}$, and was then reheated from 30 to $150{ }^{\circ} \mathrm{C}$ to obtain a second heat-flow profile. From the step change of the reversible heat flow of the second heating, $T_{\mathrm{g}}$ was determined.

The molecular weight of PS and PS/LDH composites were obtained from viscosity data. PS/LDH samples were extracted for 4 days with toluene in a Soxhlet apparatus to remove the LDH and the polymer was dried in air $(48 \mathrm{~h})$ and then in a vacuum oven at $100^{\circ} \mathrm{C}(12 \mathrm{~h})$. The results are an average of three determinations, and the Mark-Houwink constants were obtained from published data ${ }^{[28]}$.

\section{Results and discussion}

The incorporation of the azo-initiator anions in the gallery of both zinc aluminum and magnesium aluminum LDHs was investigated. As shown in Fig. 2, the coprecipitation method adopted in this study yielded well layered materials; the interlayer spacing of both materials is $1.6 \mathrm{~nm}$, but the zinc-rich LDH is more crystalline than its magnesium counterpart; at least 5 reflections at equidistant $2 \vartheta$ values are visible for this sample, which indicates that the layers are pronounced. Aging the LDHs for a week was required in order to incorporate these anions in the gallery of these LDHs; the XRD trace of a sample of ZnAl-ACPA that was prepared following the same experimental procedure, but aged for only 4 days, showed incomplete intercalation of ACPA anions into the gallery of the LDH as shown in the insert in the figure. Unlike the sample aged for 7 days, the nitrate peak (basal spacing of $0.76 \mathrm{~nm}$ ) is the dominant phase for this sample. XRD traces in Fig. 2, however, suggest successful incorporation of ACPA anions in both ZnAl-ACPA and MgAl-ACPA after 7 days and these samples are those used for further investigation.

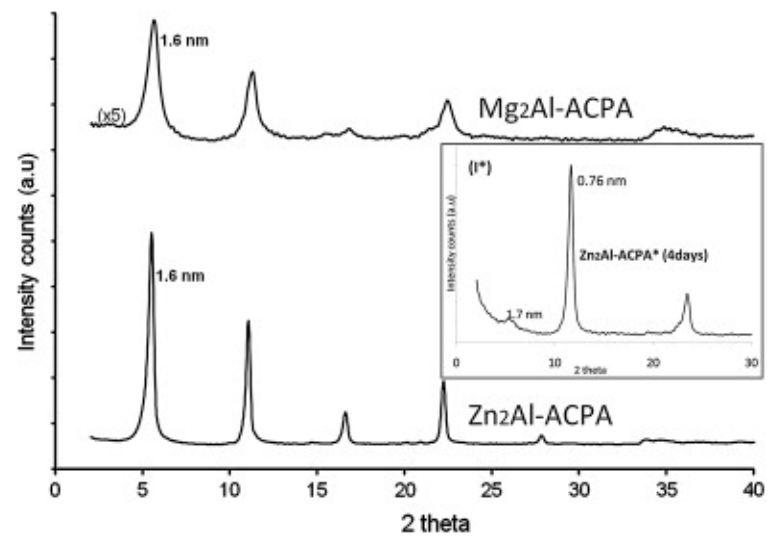

Fig. 2. XRD traces of ACPA-containing LDHs (aged for 7 days) of zinc aluminum and magnesium aluminum. The inset $\left(I^{*}\right)$ show the XRD trace of a zinc aluminum ACPA LDH that was aged for only 4 days.

The average crystallite size of both materials was determined from the Scherrer equation and found to be $29 \mathrm{~nm}$ for ZnAl-ACPA and $11 \mathrm{~nm}$ for MgAl-ACPA. This suggests a stack of 18-19 and 7 layers in the c- 
direction for ZnAl-ACPA and MgAl-ACPA, respectively. It is worth mentioning that when using LDHs as additives in polymers for various purposes, the particle size of the LDH should be in the nanometer range and the particle size distribution should be narrow $\underline{[29],[30]}$.

FTIR spectroscopy was used to confirm the presence of the azo-initiator moiety in the materials produced, as shown in Fig. 3. The more distinctive features of these spectra are the broad band around $3370 \mathrm{~cm}^{-1}$, characteristic of hydrogen bonded hydroxide in the LDHs, and the symmetric and asymmetric stretches of the carboxylate group in the $1600-1400 \mathrm{~cm}^{-1}$ region. The presence of the band around $1373 \mathrm{~cm}^{-1}$ (for MgAl-ACPA) suggests that MgAl-ACPA was not fully exchanged and contains nitrate anions along with the carboxylate azo-anion in the gallery space. The carboxylate form of ACPA, like other azo-compounds (for example 2,2'-azobis(2-cyanopropanol) (ACP)) $\frac{[31]}{}$, contains two identical asymmetric carbons and can therefore exist in meso and racemic $( \pm)$ forms. In addition, as this molecule contains an $\mathrm{N}=\mathrm{N}$ double bond, cis and trans forms may exist. It is well known that the stretching

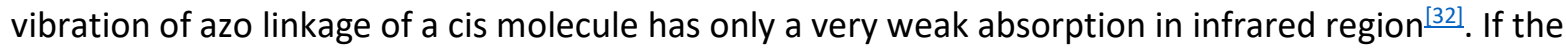
molecule is in the trans form and symmetrically substituted, the band is forbidden $\frac{[32]}{}$, which may explain why this band is not observed in Fig. 3.

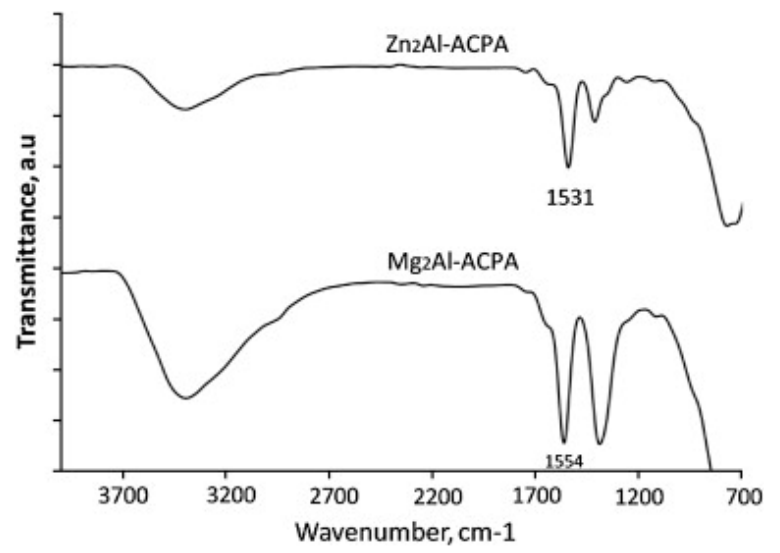

Fig. 3. ATR-IR of the initiator-containing LDHs.

Fig. 4 provides the TGA curves of ZnAl-ACPA and MgAl-ACPA run from 30 to $700^{\circ} \mathrm{C}$ at $20^{\circ} \mathrm{C} / \mathrm{min}$ in an air environment. Several events are observed in the TGA curves of these LDHs, starting with the dehydration of the layers around $120^{\circ} \mathrm{C}$. Other events include the dehydroxylation and the release of $\mathrm{N}_{2}$ from the degradation of intercalated ACPA anion to yield metal oxide at the end of the experiment. The decomposition temperature of ACPA in bulk $\left(120^{\circ} \mathrm{C}\right)$ has been reported to be intermediate to that of AIBN $\left(114^{\circ} \mathrm{C}\right)$ and $\mathrm{ACP}\left(139^{\circ} \mathrm{C}\right)^{[31]}$ the inductive effect of $\mathrm{OH}$ groups on ACP can decrease the stability of the radical formed, hence the azo decomposition takes place at a higher temperature than that of AIBN or ACPA. As for ACPA, the $\mathrm{COOH}$ group is far removed from the carbon atom next to the $\mathrm{N}=\mathrm{N}$ group thus this effect is negligible ${ }^{[31]}$. In addition to the relatively low temperature of decomposition of ACPA (relative to ACP for example), the carboxylic acid functionality of this azo compound makes it more practical to use in LDHs taking advantage of its carboxylate form to balance the negative charge of the LDH layers. 


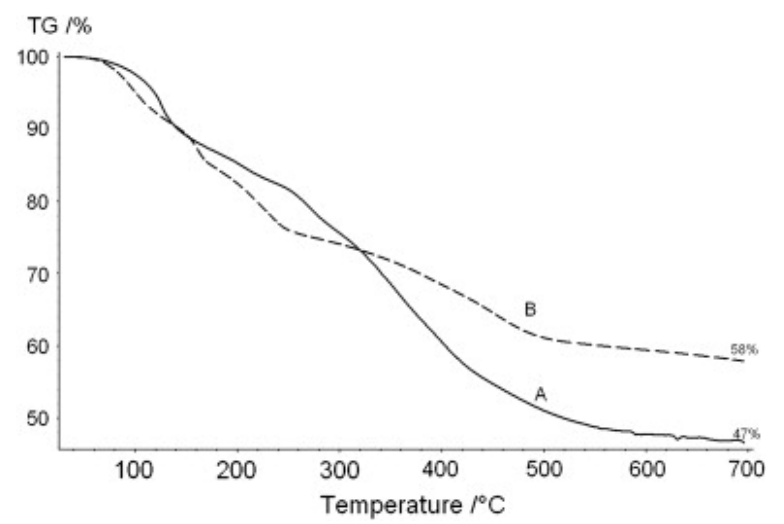

Fig. 4. TGA curves of $\mathrm{ZnAl}(\mathrm{A})$ and $\mathrm{MgAl}(\mathrm{B})$ under a nitrogen environment, from 30 to $700^{\circ} \mathrm{C}$.

\subsection{PS/LDH nanocomposites}

Heating a mixture of an organically-modified LDH and a monomer, without initiator, did not lead to the formation of a polymer composite as indicated in the experimental section; the polymerization process requires the presence of an initiator that breaks down to form radicals and start the growth of polymer chains. On the other hand, mixing the initiator-modified LDH with styrene and subsequently heating the mixture initiated the polymerization of styrene, shown by an increase in the viscosity of the mixture at the start and a hard polymer composite at the end of the reaction, highlighting the success of the polymerization process.

Dispersion of composites was monitored by both XRD and TEM. After the polymerization reactions and the evaporation of monomer in a vacuum oven, the XRD trace of the PS/3\% ZnAl-ACPA sample does not show a diffraction peak, as shown in Fig. 5A. This pattern suggests exfoliation or disordering of the LDH layers in the PS matrix, or in other words, this means that the azo-initiator intercalated in the gallery of this LDH effectively started the polymerization reaction and the styrene was polymerized from the azoinitiator chains, and was grafted on the surface of the ZnAl nanolayers. As the LDH loading is increased, the XRD patterns (Fig. 5B and $5 \mathrm{C}$ ) show a weak diffraction peak, which suggests that the galleries of LDH are expanded and the layers of LDH are partially exfoliated for both $6 \%$ and $10 \% \mathrm{ZnAl}-\mathrm{ACPA}$.

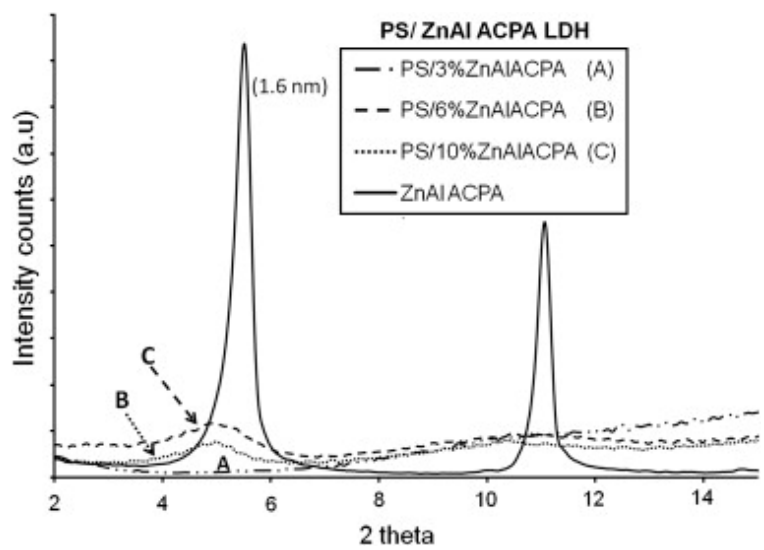

Fig. 5. X-ray diffraction traces of PS/ZnAl-ACPA systems.

The composite morphology can be directly observed via bright field transmission electron microscopy (TEM). The TEM images at low magnification are used to determine the overall dispersion of the layered 
material in the polymer, while the higher magnification image provide more detail on the nanometer scale dispersion (e.g. intercalated or exfoliated morphologies). The TEM images at both low and high magnification of PS/3\% ZnAl-ACPA nanocomposites are shown in Fig. 6. At low magnification, good dispersion of the LDH layers in the polymeric matrix is noted. However, interestingly, a few voids are also observed in these images that are tentatively correlated to the bubbling of nitrogen released during the decomposition of some azo-initiator anions that had survived the polymerization conditions, but broke apart during the preparation of the TEM samples (the samples were pressed into 4 square pieces of $1 \times 1 \times 0.1 \mathrm{~cm}^{3}$ in a hot press at $150-170^{\circ} \mathrm{C}$ for $2-3 \mathrm{~min}$ prior to microtoming them with a diamond knife as described in Experimental section). From the higher magnification images, at 3\% LDH loading, stacks of 2, 3, 4 or 5 layers separated by 10-15 nm are visible, but also single exfoliated LDH can be seen which suggests a mixed morphology. The high aspect ratio of some of LDH layers could also be visualized; the length of the majority of the layers is about $100 \mathrm{~nm}$ (but a few shorter ones of 50-100 nm are also observed), while the thickness is measured to be $1-1.5 \mathrm{~nm}$. These results suggest good dispersion of LDH into the PS matrix.

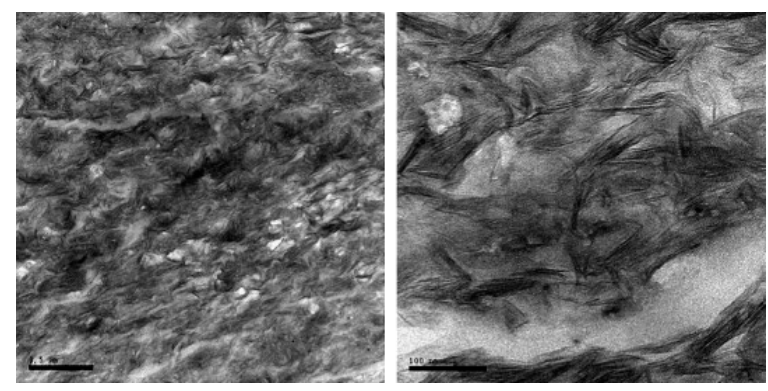

Fig. 6. Bright field TEM images of PS/3\% ZnAl-ACPA at different magnifications.

The XRD patterns of PS modified with different loadings of MgAl-ACPA are shown in Fig. 7. These patterns do not show any diffraction peak and this may suggest exfoliation of the MgAl-ACPA layers in the PS matrix or the formation of a disordered system. As evidenced by both IR and XRD studies of this LDH alone, the presence of a small amount of unexchanged nitrate anions was observed. This anion cannot initiate the polymerization of styrene; only the azo-initiator anion can accomplish this. The disappearance of both nitrate and ACPA anion diffraction peaks may suggest exfoliation, but disordered systems are another possibility.

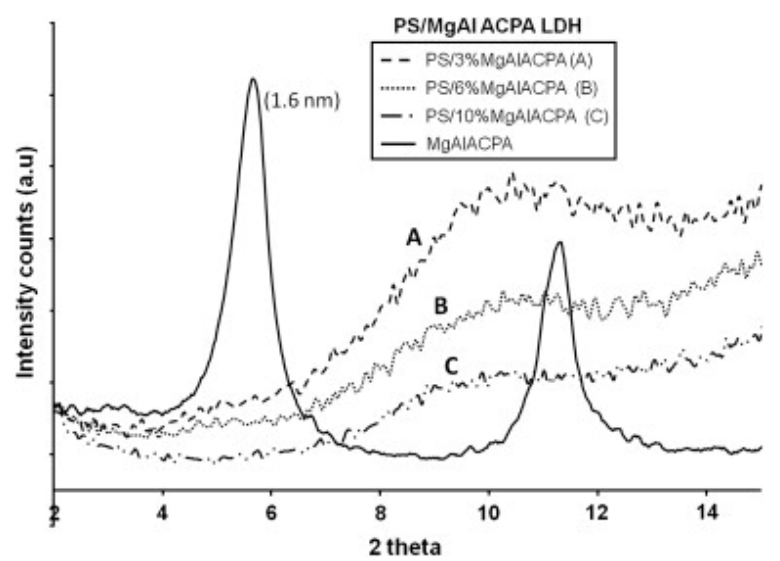

Fig. 7. X-ray diffraction traces of PS/MgAl-ACPA systems. 
TEM images of PS/3\% MgAl-ACPA were obtained and are shown in Fig. 8. The lower magnification image (on the left) reveal that the LDH layers form large agglomerates $\left(3.3 \times 1.9 \mu \mathrm{m}^{2}\right)$, well swollen by polymer. The higher magnification image (on the right) reveals individual and stacks of individual layers. Careful analysis of the high magnification image reveals a broader particle size distribution for MgAlACPA relative to $\mathrm{ZnAl}-\mathrm{ACPA} \mathrm{LDH}$. The length of MgAl-ACPA layers ranges between 20 and $100 \mathrm{~nm}$. The disappearance of XRD diffraction peaks of PS/MgAl-ACPA composites is then due to the disordering of the LDH layers as they form agglomerates. From the observation that MgAl-ACPA initiated the polymerization of styrene, one may suggest that polymer chains are grafted to the surface which would lead to the formation of exfoliated layers. It is possible that LDH layers of MgAl-ACPA agglomerate during the polymerization. Another possibility would be that only part of azo anions starts the polymerization, taking into account that from the Scherrer equation about 9 stacked layers in c-direction for MgAl-ACPA were estimated; presumably polymerization does not start within the LDH but rather on the outer surface. The differences between MgAl-ACPA and ZnAl-ACPA would then be due to differences in layers charge densities for both materials. Work must be done to evaluate these possibilities.

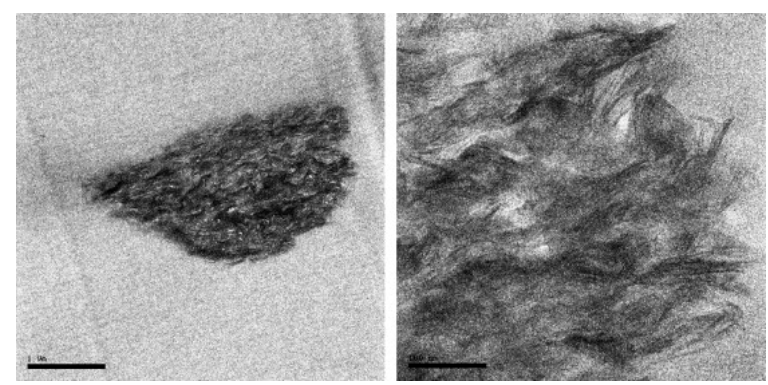

Fig. 8. Bright field TEM images of PS/3\% MgAl-ACPA at different magnifications.

\subsection{Molecular weight measurements}

The molecular weights of PS and the PS composites used in this work were obtained from viscosity data. The results, given in Table 1, are an average of three determinations, and the Mark-Houwink constants were obtained from published data. As shown in Table 1, increasing the amount of initiator from $1 \%$ to $2 \%$ resulted in a polystyrene sample with lower molecular weight, as expected. From TGA data, $3 \%$ LDH loading in PS was estimated to correspond to 1\% ACPA while 6\% LDH loading in PS was approximately equal to 2\% ACPA alone in PS. From the above estimation, if the LDH does not affect the polymerization of PS, the presence of $3 \%$ or $6 \%$ LDH should lead to polystyrene samples with molecular weights comparable with PS/1\% ACPA and PS/2\% ACPA, respectively. PS/3\% ZnAl gives polystyrene with a molecular weight of 182,000 , which is comparable to the expected molecular weight from the estimation of the initiator content in the LDH. However, with the PS/3\% MgAl sample, the molecular weight recorded is 246,000 . This might be due to the smaller content of initiator-anion in this LDH relative to its zinc-counterpart as was earlier suggested by the presence of nitrate from IR experiments. In fact, the small nitrate content still present in MgAl-ACPA LDHs means that less initiator-anion is present in the $\mathrm{LDH}$, and then, a relatively higher molecular weight of the polymer composites is expected. In general, these data suggest that the initiator on the LDH decomposes and leads to polymerization and that the presence of the LDH has no other effect on this process.

Table 1. Molecular weights from viscosity measurements. 


\begin{tabular}{|l|l|l|}
\hline PS (1\% ACPA) & 167,000 & 4000 \\
\hline PS (2\% ACPA) & 57,000 & 3000 \\
\hline PS/3\% ZnAI ACPA & 182,000 & 4000 \\
\hline PS/3\% MgAl ACPA & 246,000 & 4000 \\
\hline
\end{tabular}

\subsection{Glass transition temperature, $T_{g}$}

The glass transition is an important thermal effect that can be used to characterize polymers and other amorphous or semicrystalline materials. A variation of the glass transition of composites relative to the virgin polymer prepared under identical condition can provide evidence of possible specific interaction between the particles and the polymer matrix.

In this study, it was observed that these PS/LDH composites undergo an enthalpy relaxation, possibly because of internal stresses built up in the materials during processing. As a result, slight peaks show up before or after the $T_{\mathrm{g}}$. To account for this, all samples are heated from 30 to 130 at $20^{\circ} \mathrm{C} / \mathrm{min}$, then cooled at a similar ramp rate and kept at $30{ }^{\circ} \mathrm{C}$ for about a minute before being heated again from 30 to $150{ }^{\circ} \mathrm{C}$. The $T_{\mathrm{g}} \mathrm{s}$ reported in Table 2 are then recorded on this second run and $T_{\mathrm{g}}$ is more clearly seen.

Table 2. Glass transition temperature of PS with different concentrations of LDHs.

\begin{tabular}{|l|l|}
\hline Material & Glass transition temperature, $\boldsymbol{T}_{\mathbf{g}}$ \\
\hline PS & 82.1 \\
\hline PS-3\% ZnAl-ACPA & 76.8 \\
\hline PS-6\% ZnAl-ACPA & 80.5 \\
\hline PS-10\% ZnAl-ACPA & 76.2 \\
\hline PS-3\% MgAl-ACPA & 73.4 \\
\hline PS-6\% MgAl-ACPA & 53.6 \\
\hline PS-10\% MgAl-ACPA & 50.6 \\
\hline
\end{tabular}

Note: the reported value is an average of 4 determinations.

Reduction in the glass transition temperature $\left(T_{\mathrm{g}}\right)$ was found to be greater for magnesium-containing samples, as shown in Table 2, while the presence of zinc-containing sample did not significantly lower the $T_{\mathrm{g}}$. It is possible that MgAl-ACPA imposes a constrained crystallization process, as a result of a restriction imposed on the chain packing by the grafting of the polymer chains on the LDH layers, and results in an increasing net free volume in the amorphous phase and hence reduces $T_{\mathrm{g}}$. The presence of the layers of MgAl-ACPA in PS enhances polymer dynamics due to extra free volume which results in the $T_{\mathrm{g}}$ depression. It is known that nanoparticles that have a higher specific surface area and, in a well dispersed system, interaction of polymer chains with the surface of the particle, can drastically alter the chain kinetics, increasing or decreasing the $T_{\mathrm{g}}$ of the polymer matrix $[33]$, [34]. As the filler size enters the nanoregion, the volume fraction of the interaction region in the nanocomposites increases with increasing interface area of the polymer and the nanofillers ${ }^{[35]}$. This becomes the basis for potentially tremendous changes in the nanocomposite properties. An analogous explanation for the depression of the glass transition temperature has been reported in chemically crosslinked low-density polyethylene and their blends with ethylene vinyl acetate copolymer $\stackrel{[36]}{\text {. }}$

From XRD traces of the LDH alone, ZnAl-ACPA is more crystalline than MgAl-ACPA, and the Scherrer Equation suggests more stacked layers for ZnAl-ACPA compared to MgAl-ACPA (29 stacked layers for ZnAl-ACPA vs to 11 for MgAl-ACPA). From the TEM images, ZnAl-ACPA is also better dispersed in PS than is MgAl-ACPA which would suggest a better interaction between the LDH filler with the polymer matrix. It is well known that composite properties can change with the dispersion state, geometric 
shape, surface properties, particle size and particle size distribution ${ }^{[2]}$ [37] . However, in this study, the differences in the dispersion state of these LDH additives in PS and also the differences in particle size distribution observed in the TEM images of MgAl-ACPA layers compared to ZnAl-ACPA layers may be the reason for the differences in the measured $T_{\mathrm{g}} \mathrm{S}$ of the two systems.

\subsection{Thermal properties of PS/LDH systems}

The thermal stability of composites was evaluated by thermogravimetry and the TGA curves of PS/MgAl-ACPA and PS/ZnAl-ACPA composites are provided in Fig. 9. When the initiator-intercalated LDH is used to polymerize styrene, the resulting polymer shows an additional step in the TGA in the temperature range $180-220^{\circ} \mathrm{C}$ which is probably due to the degradation of the $\mathrm{LDH}$, if one considers the degradation pathways of the LDH alone, as shown in the same figure. The presence of LDH causes a decrease of about $5^{\circ}$ in the main degradation of PS. It is worth mentioning that while the dispersions for the two systems are different (nanodispersion observed for PS/ZnAl-ACPA while microdispersion is noted with PS/MgAl-ACPA), similar TGA patterns were observed for either system. It is then likely that the thermal stability of the additive alone play a more important role in the thermal stability of the composites relative to interaction defined by polymer-LDH combination.
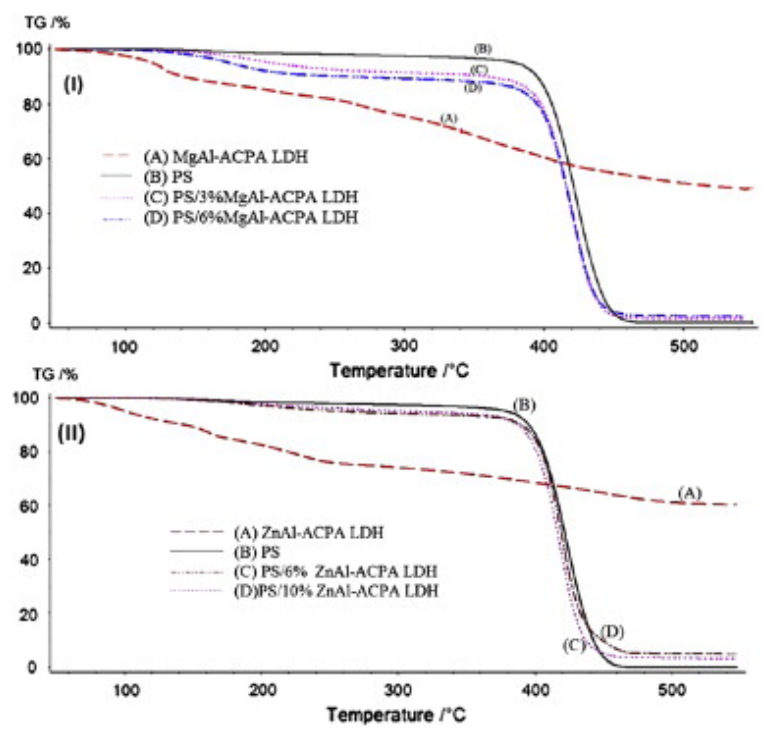

Fig. 9. TGA curves of (I) PS/MgAl-ACPA and (II) PS/ZnAl-ACPA systems in nitrogen environment at $20^{\circ} \mathrm{C} / \mathrm{min}$.

\subsection{Flammability properties of PS/LDH systems}

The flammability of PS/LDHs (LDH = ZnAl-ACPA and MgAl-ACPA) was investigated using the cone calorimeter. The parameters of interest are the time to ignition, which is usually smaller for nanocomposites than the virgin polymer; the peak heat release rate (PHRR); the percentage reduction in this value caused by nanocomposite formation; the time to PHRR; the total heat released (THR); the mass loss rate (AMLR); and the volume of smoke produced (VOS). The change in the peak heat release rate is commonly explained by the decrease in the mass loss rate ${ }^{[27],}$ [38]. The heat release rate curve is usually considered to be the most important parameter in fire retardancy studies. The reduction in PHRR is important for fire safety, as PHRR represents the point in a fire where heat is likely to propagate further, or ignite adjacent objects ${ }^{[39]}$. All the data reported here are the averages of three 
determinations and were collected during a single run of the cone for better comparison between the data.

The cone calorimetric results of PS/LDH systems are summarized in Table 3 . The best reduction in PHRR (35\%) is obtained with PS/10\% ZnAl-ACPA; at a similar loading, MgAl-ACPA gives 24\% reduction. Lower loadings of LDH do not offer great improvement in fire properties. Also, the magnesium-containing systems greatly lower the time to ignition from 42 to less than $10 \mathrm{~s}$. LDHs have been reported to perform well with polar polymer like PMMA, at 10\% LDH loading reductions greater that $50 \%$ are

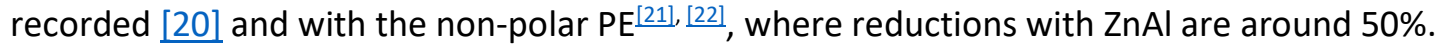
Polystyrene, also a relatively non-polar polymer seems incompatible with these non-functionalized additives. The search for anions to enable better compatibilization of LDHs with this polymer and the choice of the right combination of metals and ratio of metals (trivalent to divalent metal cations) are keys in developing PS/LDH systems with enhanced flammability properties.

Table 3. Cone summary results of PS modified with ACPA-containing LDHs at $35 \mathrm{~kW} / \mathrm{m}^{2}$.

\begin{tabular}{|c|c|c|c|c|c|c|}
\hline Formulation & $\begin{array}{l}\text { PHRR (kW/m²) (\% } \\
\text { Reduction) }\end{array}$ & $t_{\text {PHRR }}(s)$ & $\begin{array}{l}\text { THR } \\
\left(\mathrm{MJ} / \mathrm{m}^{2}\right)\end{array}$ & vos (I) & $\begin{array}{l}\text { AMLR } \\
\left(\mathrm{g} / \mathrm{sec} \mathrm{m}^{2}\right)\end{array}$ & $t_{\text {ign }}(\mathrm{sec})$ \\
\hline PS & $1348 \pm 34(\mathrm{NA})$ & $103 \pm 4$ & $91 \pm 3$ & $2973 \pm 58$ & $33.3 \pm 1.6$ & $42 \pm 5$ \\
\hline $\begin{array}{l}\text { PS/3\% ZnAl- } \\
\text { ACPA }\end{array}$ & $1206 \pm 37(11)$ & $105 \pm 12$ & $94 \pm 6$ & $3099 \pm 203$ & $31.0 \pm 0.4$ & $30 \pm 3$ \\
\hline $\begin{array}{l}\text { PS/6\% ZnAl- } \\
\text { ACPA }\end{array}$ & $1239 \pm 1(8)$ & $107 \pm 15$ & $109 \pm 3$ & $3369 \pm 237$ & $28.0 \pm 0.3$ & $12 \pm 2$ \\
\hline $\begin{array}{l}\text { PS/10\% ZnAl- } \\
\text { ACPA }\end{array}$ & $873 \pm 12(35)$ & $140 \pm 1$ & $104 \pm 3$ & $3951 \pm 85$ & $22.1 \pm 0.5$ & $18 \pm 3$ \\
\hline $\begin{array}{l}\text { PS/3\% MgAl- } \\
\text { ACPA }\end{array}$ & $1154 \pm 50(14)$ & $98 \pm 13$ & $93 \pm 1$ & $3200 \pm 201$ & $31.3 \pm 4.5$ & $8 \pm 2$ \\
\hline $\begin{array}{l}\text { PS/6\% MgAl- } \\
\text { ACPA }\end{array}$ & $1163 \pm 53(14)$ & $109 \pm 3$ & $105 \pm 2$ & $3171 \pm 64$ & $27.8 \pm 1.1$ & $8 \pm 0$ \\
\hline $\begin{array}{l}\text { PS } / 10 \% \text { MgAl- } \\
\text { ACPA }\end{array}$ & $1031 \pm 9(24)$ & $84 \pm 22$ & $102 \pm 3$ & $3297 \pm 92$ & $25.2 \pm 1.4$ & $5 \pm 0$ \\
\hline
\end{tabular}

Note: PHRR is the peak of heat release rate; (\%red.) is the \% reduction relative to the control sample; $t$ PHRR is the time to PHRR; THR is the total heat released; VOS is the volume of smoke; AMLR; $t_{\text {ign }}$ is the time to ignition.

The reductions in peak heat release rate observed for PS/LDH systems in this work should be compared to previous results on PS modified with a series of MgAl LDHs containing long chains carboxylates $\frac{[20]}{2}$. In that study, the TEM images of the composites reveal better dispersion for the $\mathrm{C} 11$ and $\mathrm{C} 22$ modified $\mathrm{LDH}$ relative to other PS/LDH systems. The cone results indicated, however, that MgAl-C10 and MgAlC12 give the largest reduction in PHRR in that series. The current results show that using initiatormodified LDH to obtain new PS/LDH composites effectively improves dispersion. No significant improvements in reduction in PHRR are observed, however, and the thermal stability of the composites is inferior to that of the pristine polymer due to the early degradation of the additive alone. Dispersion is important if the additive is not to have an adverse effect of mechanical properties of composites. The current results show a fair correlation between the reduction in PHRR and dispersion since TEM images reveal better dispersion for ZnAl-ACPA and this also give the lowest PHRR. It is possible that compatibility between PS and LDH may be further improved by incorporating rings in the organic surfactant of LDH, and that the composite properties could be further enhanced by controlling the LDH particle size distribution. 


\section{Conclusions}

When styrene is bulk polymerized in the presence of an initiator-containing $\mathrm{LDH}, \mathrm{ZnAl-ACPA}$ and MgAlACPA, an intercalated-exfoliated morphology is observed for composites of ZnAl-ACPA while MgAlACPA leads to microcomposite formation. The current results show good correlation between the reduction in PHRR and dispersion; the reduction in the peak heat release rate for 10\% $\mathrm{ZnAl}-\mathrm{ACPA}$ is $35 \%$ compared to the pristine polymer while a $24 \%$ reduction is recorded for MgAl-ACPA at a similar loading. The LDH additives affect the glass transition temperatures of PS differently; depression of $T_{\mathrm{g}}$ is observed when MgAl-ACPA is used to polymerize styrene while ZnAl-ACPA seems not to impact $T_{\mathrm{g}}$. While LDH materials have been successfully used as fire retardant additives for polymers like PMMA, PE and PP where reductions above $50 \%$ have been recorded, the design of a type of $L D H$ that is a good fire retardant for polystyrene is still a challenge.

\section{Acknowledgements}

This work was partially supported by the US Department of Commerce, National Institute of Standards and Technology, Grant 60NANB6D6018. We thank Dr David Berzins for the use of the DSC and his useful discussion on the interpretation of glass transition temperature data. We also thank Emily Skibinski, a summer student in the laboratory, for the work on the DSC.

\section{References}

[1] Velu S, Swamy CS. Appl Catal A 1997;162:81.

[2] Evans DG, Duan X. Chem Commun 2006;5:485.

[3] Leroux F, Besse JP. Chem Mater 2001;13:3507.

[4] Kickelbick G. Prog Polym Sci 2003;28:83.

[5] Caseri W. Macromol Rapid Commun 2000;21:705.

[6] Utracki LA, Sepehr M, Boccaleri E. Polym Adv Technol 2007;18:1.

[7] Jordan J, Jacob KI, Tannenbaum R, Shart MA, Jasiuk I. Mater Sci Eng A 2005;393:1.

[8] Zheng J, Ozisik R, Siegel RW. Polymer 2005;46:10484.

[9] Friedrich K, Zhang Z, Schlarb AK. Compos Sci Technol 2005;65:2329.

[10] Hergeth W, Steinau U, Bittrich H, Simon G, Schmutzler K. Polymer 1989;30:254.

[11] Cao YM, Sun J, Yu DH. J Appl Polym Sci 2002;83:70.

[12] Pham JQ, Mitchell CA, Bahr JL, Tour JM, Krishanamoorti R, Green PF. J Polym Sci 2003;41:3339.

[13] Ash BJ, Schadler LS, Siegel RW. Mater Lett 2002;55:83.

[14] Vollenberg PHT, DeHaan JW, Van de Ven LIM, Heikens D. Polymer 1989;30:1663.

[15] Nielsen L, Landel R. Mechanical properties of polymers and composites. New York: Marcel Dekker; 1994.

[16] Mattsson J, Forrest JA, Brjesson L. Phys Rev E 2000;62:5187.

[17] Wang GA, Wang CC, Chen CY. Polym Degrad Stab 2006;91:2443.

[18] Qiu L, Chen W, Qu B. Colloid Polym Sci 2005;283:241.

[19] Manzi-Nshuti C, Wang D, Hossenlopp JM, Wilkie CA. J Mater Chem 2008;18:3091.

[20] Nyambo C, Songtipya P, Manias E, Jimenez-Gasco MM, Wilkie CA. J Mater Chem 2008;18:4827.

[21] Costantino U, Gallipoli A, Nocchetti M, Camino G, Bellucci F, Frache A. Polym Degrad Stab 2005;90:586. 
[22] Manzi-Nshuti, C.; Songtipya, P.; Manias, E.; Jimenez-Gasco, M. M.; Hossenlopp, J.M.; Wilkie, C.A. submitted.

[23] Manzi-Nshuti, C.; Hossenlopp, J.M.; Wilkie, C.A. Manuscript in preparation.

[24] Zhu J, Uhl FM, Morgan AB, Wilkie CA. Chem Mater 2001;13:4649.

[25] Nyambo C, Kandare E, Wang D, Wilkie CA. Polym Degrad Stab 2008;93:1656. [26] Bao YZ, Huang ZM, Weng ZX. J Appl Polym Sci 2006;102:1471.

[27] Gilman JW, Kashiwagi T, Nyden M, Brown JET, Jackson CL, Lomakin S, et al. In: Al-Malaika S, Golovoy A, Wilkie CA, editors. Chemistry and technology of polymer additives. Oxford: Blackwell Scientific; 1999. p. 249.

[28] Kurata M, Tsunashima Y. In: Brandrup J, Immergut EH, Grulke EA, editors. Polymer handbook. 4th ed. New York: Wiley; 1999. p. 1-83. p VII.

[29] Xu G, Li L, Zhang C, Evans DG, Duan X. Chin J Appl Chem 1999;16:104.

[30] Adachi-Pagano M, Forano C, Besse JP. J Mater Chem 2003;13:1988.

[31] Cheikhland T, Tighzert L, Pascault JP. Angew Makromol Chem 1998;256:49.

[32] Bellamy L. The infrared spectra of complex molecules. 3rd ed. London: Chapman and Hall; 1975. p. 294.

[33] Yang M, Dan Y. Colloid Polym Sci 2005;284:243.

[34] Weng CC, Wei KH. Chem Mater 2003;15:2936.

[35] Sun Y, Zhang Z, Moon KS, Wong CP. J Polym Sci Part B Polym Phys 2004;42:3849.

[36] Khonakdar HA, Jafari SH, Ha“ssler R. J Appl Polym Sci 2007;104:1654.

[37] Hanemann T. Ceramics Int 2008;34:2099.

[38] Gilman JW, Jackson CL, Morgan AB, Harris R, Manias E, Giannelis EP, et al. Chem Mater 2000;12:1866.

[39] Babrauskas V, Peacock RD. Fire Safety J 1992;18:255. 